\title{
ENSEJOS DA EDUCAÇÃO A DISTÂNCIA EaD PARA A FORMAÇÃO CONTINUADA NO ESTADO DO PIAUÍ
}

\section{OPPORTUNITIES OF THE EDUCATION DISTANCE EaD FOR THE TRAINING CONTINUING ON THE PIAUÍ STATE}

\author{
José Geovânio Buenos Aires Martins \\ geovaniofecr@gmail.com \\ Especiealista em Docência do Ensino Superior \\ Professor Colaborador da Faculdade Ágora, \\ Piauí, Brasil. \\ http://lattes.cnpq.br/0140858987121365 \\ Ana Paula de Oliveira e Silva \\ tutoriaibpex_picos@ hotmail.com \\ Especialista em Tutoria em Educação a Distância e em Formação de Docentes \\ Gestora e Tutora Presencial da UNINTER (PAP-PICOS) Piauí, Brasil \\ Maria Greuvânia Buenos Aires Martins \\ marygreu@gmail.com \\ Especialista em Docência do Ensino Superior \\ SEME - Picos, Piaú, Brasil \\ http://lattes.cnpq.br/7320023082084119
}

\section{RESUMO}

O presente artigo tem como tema de estudo: Ensejos da Educação a Distância para a formação continuada no estado do Piauí. O principal objetivo desta investigação; foi investigar o surgimento e desenvolvimento da Educação a Distância no Brasil e, sua verdadeira contribuição para a formação continuada de professores da educação básica do estado do Piauí. Haja vista, que a $\mathrm{EaD}$, tem levado formação de qualidade aos diferentes espaços não contemplados por Instituições de Ensino Presencial. Para-se alcançar tudo isso, fez-se uma pesquisa bibliográfica, como não poderia deixar de ser, e uma pesquisa de campo participante, pois somente depois da análise dos dados coletados é que se pôde sugerir novas estratégias pedagógicas e administrativas, para o campo da EaD. Portanto, é necessário novas pesquisas no campo da EaD e da formação continuada de professores, pois os trabalhos existentes ainda o são poucos e os que existem não apresentam as soluções exatas para os problemas pelos os quais passam a EaD e a formação continuada de professores em especial.

Palavras-chave: EaD. Formação Continuada. Professores de Educação Básica.

\section{ABSTRACT}

This article is the subject of study: Education longings Distance to continuing education in the state of the Piauí. The main objective of this research; It was to investigate the emergence and 
development of distance education in Brazil and, its real contribution to the continuing education of teachers in the Piauí state of basic education. Considering that EaD has led quality training to different areas not covered by Institutions Face Teaching. To be achieved all this, there was a literature search, as it should be, and a participant field research, because only after the analysis of the collected data is that it might suggest new pedagogical and administrative strategies for the field of the EaD. It is therefore necessary further research in the field of the $\mathrm{EaD}$, and the continuing education of teachers because existing jobs still are few and those that exist do not have the exact solutions to the problems by which start to EaD and continuing education in particular the teachers.

Keywords: EaD. Continuing Education. Basic Education Teachers.

\section{INTRODUÇÃO}

O presente artigo traz uma discussão acerca da EaD, como proponente de formação continuada para professores da educação básica do estado do PI, que não dispõem de tempo e/ou condições financeiras para continuar se qualificando. É bem verdade, que o mercado de trabalho está cada vez mais exigente no quesito contratação de quadro de pessoal; em virtude do capitalismo exacerbado e, das novas tecnologias que despontam cada vez mais. O que tem provocado uma grande procura pela $\mathrm{EaD}$.

Muitos são os fatores que têm levado não somente os profissionais docentes da educação básica do estado do Piauí, a procurar a $\mathrm{EaD}$, e que dentre eles podemos citar: localização geográfica e falta de recursos financeiros, como um dos principais motivos. Existem outros? Sim! Portanto, não existe espaço para a descrição de todos os motivos existentes. Tendo sido, priorizado aqueles cruciais para o desenvolvimento desse artigo.

Portanto, a Educação a Distância, surge, conforme Silva (2011, p. 1), como a solução imediata para a qualificação de profissionais do setor de educação; levando formação inicial e continuada aos lugares mais remotos deste país.

E, nesta perspectiva o estado do Piauí, evoluiu bastante. A cidade de Picos-PI, é um exemplo desse crescimento, pois através do Centro Universitário Internacional UNINTER; muitos profissionais da educação básica em especial tem dado continuidade a sua formação, através de cursos de licenciaturas, segunda licenciatura e Pós-Graduação (lato-sensu); este último objeto de investigação desse estudo, como proponente para a formação continuada de professores da educação básica do estado do Piauí.

O Brasil, hoje, é referência nessa nova modalidade de ensino e, quando se fala da EaD, o leitor é levado a refletir sobre um passado remoto, entretanto quando se fala da $\mathrm{EaD}$ com propósito de formação e diplomação em nível de $3^{\circ}$ grau e, ainda de cursos de Pós-Graduação, 
temos uma situação amplamente nova no Brasil; e atualmente contemplada pela Lei de Diretrizes e Bases da Educação Nacional LDBEN.

Porquanto, nesta modalidade de ensino o aluno deve ser o principal responsável pela evolução acadêmica de sua própria formação, pois não existe professor presencial. $\mathrm{O}$ acompanhamento acontece via ambiente virtual de aprendizagem, porém isso, não implica em uma educação sem qualidade, pelo contrário a $\mathrm{EaD}$ tem conseguido se destacar quando comparada com cursos da modalidade presencial.

À EaD, portanto, já superou todos os preconceitos que põem em dúvida a sua qualidade? Não! Existem aqueles que ainda duvidam do ensino ministrado através da EaD, contudo o que se sabe é que a qualidade do ensino, não passa pelo o viés da presença de um professor presencial, apenas. Sob o mesmo ponto de vista, Moraes (2010, p. 13), diz que a EaD não somente leva educação de qualidade, para aqueles que não teriam como estudar em uma universidade regular; ela ampliou o poder de desenvolvimento da educação. A EaD, é mais uma aliada na luta pelo acesso ao conhecimento de qualidade.

Dá-se a entender que a $\mathrm{EaD}$, além dos baixos custos, representa uma opção para aqueles que não dispõem de tempo, ou que, são pais, trabalhadores e que por sua vez não podem se ausentar do lar. Assim sendo, a Educação a Distância, tem sido mais uma nova ferramenta eficaz no avanço de projetos traçados e desenvolvidos pelo o Ministério da Educação; contemplando a formação continuada não somente de professores e profissionais da educação, mas de profissionais liberais e alunos interessados em qualificação; sendo permitido aos estudantes de EaD, qualificação segura. Melhor; sem ter que deixar seu espaço familiar, cultural e trabalhista.

O que difere, portanto a EaD da Educação Presencial? Se você se sentiu atraído pela pergunta! Convidamos você leitor, a descobrir essa resposta ao longo do desenvolvimento desse artigo.

Sendo assim, o objetivo maior dessa pesquisa é: Investigar o surgimento e desenvolvimento da Educação a Distância no Brasil e sua verdadeira contribuição para a formação continuada de professores da educação básica do estado do Piauí.

O presente artigo, também faz uma discussão ao longo do seu desenvolvimento; sobre o contexto histórico da educação a distância - contribuição - e implicações para à implantação da $\mathrm{EaD}$ no Brasil; EaD o que é isso? EaD no contexto da LDBEN, formação continuada de professores em ambientes de aprendizagem virtual AVA; e, modalidade via E-learning o que é isso? 


\section{CONTEXTO HISTÓRICO DA EDUCAÇÃO A DISTÂNCIA - CONTRIBUIÇÃO - E IMPLICAÇÕES PARA À IMPLANTAÇÃO DA EAD NO BRASIL}

A história da $\mathrm{EaD}$ como propósito de formação e certificação em solo brasileiro não é tão antiga, pois somente depois da aprovação da última LDBEN, é que se prioriza mesmo que de forma tímida a EaD como educação. Portanto, antes de iniciarmos uma abordagem histórica da educação a distância no Brasil, conhecer um pouco mais sobre esse novo modelo de educação é importante.

Quando se fala da EaD, portanto, ela surgiu exatamente quando? Onde? Litto; Formiga et al. (2012, p. 2), informa que o surgimento da EaD e que serve de experiência para sua implantação no Brasil, não é tão antigo também. A EaD surgiu na Inglaterra, logo após a $2^{\text {a }}$ Guerra Mundial, e a divulgação de um relatório, conhecido pela história inglesa como: Relatório Robbins (1963).

Litto; Formiga et al. (2012, p. 2), acrescenta que a expansão da EaD, na Inglaterra, e que serviu de inspiração para sua implantação no Brasil; foi uma iniciativa dada, pelo o governo do $1^{\mathrm{o}}$ ministro de Harold Wilson, cuja intenção era corrigir o enorme número de desassistidos pela educação politécnica e de nível superior.

A implantação oficial da $\mathrm{EaD}$, como propósito de educação, formação e certificação na Inglaterra, aconteceu oficialmente, segundo Litto; Formiga et al. (2012, p. 2), em 8 de setembro do ano de 1963, com a criação da primeira Universidade Aberta do Mundo, denominada na literatura de Universidade do Ar. Mas, como uma história inglesa pode afetar diretamente o universo educacional brasileiro?

Litto; Formiga et al. (2012, p. 2), afirmam que o Brasil, fez um acordo com os ingleses; copiando o modelo de $\mathrm{EaD}$, desenvolvido pela Universidade do Ar, que na época já tinha sido implantado ou adaptado em vários países do mundo. Eles acrescentam ainda que, a EaD brasileira foi uma iniciativa da Universidade de Brasília UnB, cujo parecer foi dado pelo o conselheiro do Conselho Federal de Educação, Newton Lins Buarque Sucupira, que na época sugeriu a criação da EaD no nosso país; fundamentando sua proposta, com a experiência desenvolvida pelos ingleses.

No Brasil, a EaD, foi oficialmente implantada segundo Litto; Formiga et al. (2012, p. 3), no mês de fevereiro de 1979, após assinatura de convênio da UnB com a Universidade do Ar, hoje conhecida e respeitada mundialmente por UKOU.

Após esse cenário revolucionário na história da educação brasileira, e em especial da EaD. Quais vantagens essa nova modalidade de ensino garante aos seus estudantes? Litto; Formiga et al. (2012, p. 2), afirmam que são muitas as vantagens, sendo elas: 
1) oferecer ensino de qualidade a grandes contingentes humanos;

2) ser mais eficaz que os métodos tradicionais, por alguns chamado, depreciativamente, de 'talk and chalk' em português 'cuspe e giz';

3) ser menos custoso que o método tradicional - em 1979, o custo de um aluno da OKOU era 60 por cento mais baixo que o de outras universidades;

4) evitar as macroconcentrações de alunos, servidores e professores, que exigem grandes edifícios, laboratórios e infraestrutura;

5) viabilizar o desenvolvimento rural com a qualificação dos que habitam essa região;

6) reduzir o fluxo migratório para os centros urbanos;

7) assegurar o ensino superior de alto nível onde não há instituições para oferecê-lo.

É verdade, que além, do baixo custo, a EaD tem levado educação de qualidade aos lugares mais distantes do nosso país em especial. Porquanto, a EaD, foi motivo de muitas discussões ao passo de sua implantação, mas porque tudo isso? Existe uma crença cultural brasileira que somente o ensino tradicional regido por professores presenciais, traz resultados positivos. Seria essa uma verdade absoluta?

Na educação não se busca por verdades absolutas, mas pelo desenvolvimento daqueles que estão em busca de uma qualificação e, a EaD brasileira, não foge aos padrões da educação presencial, pelo contrário até têm superado alguns dos cursos da modalidade presencial no quesito desempenho de seus alunos, e quem confirma essa realidade é Litto; Formiga et al. (2012, p. 4):

[...] os resultados do Exame Nacional de Desempenho dos Estudantes (Enade), das 13 áreas em que se podem comparar estudantes da educação presencial com aqueles a distância, observa-se que em sete - administração, biologia, ciências sociais, física, matemática, pedagogia e turismo - os alunos de curso a distância foram melhores do que os alunos de aulas presenciais.

Essa realidade é mais que importante para o Brasil, pois põe fim a um preconceito cultural; a EaD, da forma, que se apresenta em resultados avaliados por iniciativa do MEC, conquistou o seu lugar de destaque na educação brasileira. O que tem levado a um crescimento acelerado da EaD no nosso país. Prova disso, citando Litto; Formiga et al. (2012, p. 4), é o crescente aumento entre 2003 e 2006, no número de cursos desta modalidade; passando de 52 cursos para 349; o número de matriculados também teve um salto quantitativo, atingindo 315 por cento. E segundo a Abed, no ano de 2007, já eram mais de 2 milhões de brasileiros de todos os recantos desse país, que estavam matriculados em um curso a distância.

A tabela abaixo, só reforça o que já foi apresentado. E dá destaque para cursos de pósgraduação lato-sensu, objeto de investigação desse estudo como proponente para a formação continuada de educadores através da EaD. 
Tabela 1 - Número de alunos por tipo de curso e nível de credenciamento (2005-2006)

\begin{tabular}{l|c|c}
\hline Tipo de curso/credenciamento & $\mathbf{2 0 0 5}$ & $\mathbf{2 0 0 6}$ \\
\hline Graduação, tecnológico e pós-graduação - credenciamento federal & 300.826 & 575.709 \\
\hline $\begin{array}{l}\text { Educação de jovens e adultos (EJA), fundamental, médio e técnico - credenciamento } \\
\text { estadual }\end{array}$ & 203.378 & 202.749 \\
\hline Total de alunos & 504.204 & 778.458 \\
\hline \multicolumn{2}{c}{ Fonte: (MAIA; MATTAR, 2007, p. 33). }
\end{tabular}

Não se pode negar a evolução da $\mathrm{EaD}$ nos últimos anos. O estigma de educação para as minorias, foi quebrado. Hoje a $\mathrm{EaD}$, é a educação do presente e do futuro, pois através da $\mathrm{EaD}$, o Brasil pode oferecer educação e educação de qualidade a baixo custo, o que não é possível ainda através da modalidade presencial, uma vez que, a modalidade presencial demanda uma maior concentração de investimentos.

\subsection{EaD o que é isso?}

Tratar da EaD, é falar dos avanços dessa nova forma de fazer educação no Brasil. Portanto, é de se considerar que a EaD não ocorre somente com o uso de computadores, da plataforma Ambiente Virtual de Aprendizagem AVA.

O que seria então este ensino através da EaD? Ele é garantia de aprendizagem para o aluno?

A primeira pergunta, citando, Faria (2011, p. 11), pode ser respondida da seguinte maneira; na EaD, o estudante é o principal responsável pelo o sucesso do seu ensinoaprendizagem, portanto não é descartada a interação aluno-professor-tutor, através das várias metodologias disponíveis em AVA, onde o aluno consegue interagir em tempo real.

A segunda proposição já foi respondida anteriormente, portanto mencionando Litto; Formiga et al. (2012, p. 4), a EaD tem se destacado no Brasil, e o que antes era criticado pelo o MEC, hoje recebe apoio unânime; tendo sido criada uma Secretaria de Educação a Distância para prestar apoio aos projetos desenvolvidos pela $\mathrm{EaD}$, o que comprova sua eficiência, a baixo custo de mercado; principal motivo para a expansão da EaD no Brasil.

$\mathrm{Na} \mathrm{EaD}$, o conceito de separação física entre alunos e professor, também já foi superado, pois segundo Sousa et al. (2012, p. 3):

[...] os conceitos de presença e distância na sociedade contemporânea têm sofrido profundas alterações, principalmente no que tange às formas de ensinar e aprender. Isso porque existe hoje a possibilidade de que a interação educacional seja mediada por espaços virtuais, nos quais é possível se valer dos mais variados tipos de mídias disponíveis. 
As principais mídias disponíveis no ensino de $\mathrm{EaD}$, a partir de uma experiência vivenciada pelos autores desse artigo são elas: o e-mail, o chat, a tutoria, o fórum, a vídeoaula, a aula-interativa, etc.

Ainda segundo Belloni (2012, p. 26), a EaD, “[...] é um subconjunto de todos os programas educacionais caracterizados por grande estrutura $[\ldots] ”$.

$\mathrm{O}$ processo de ensino-aprendizagem através da $\mathrm{EaD}$, da forma como tem sido estruturado; continuará crescendo, crescendo e crescendo, pois a $\mathrm{EaD}$, já faz parte da vida dos brasileiros que buscam uma educação de qualidade a um custo cada vez mais acessível.

Enfim, a EaD, segundo Almeida (2003, p. 332), é uma educação que mesmo a longa distância, pode-se realizar por diferentes meios (correspondência postal ou eletrônica, rádio, televisão, telefone fixo e/ou celular, fax, computador com acesso a banda larga, etc.).

\subsection{EaD no contexto da LDBEN}

Litto; Formiga et al. (2012, p. 3), informa, que o Brasil, ainda está atrás de países como Coreia do Sul, que há cinquenta anos atrás figurava entre os países mais pobres do planeta. Portanto, os sul-coreanos investiu em EaD, e hoje a Coreia do Sul, concentra forte riqueza econômica; a $\mathrm{EaD}$, por vezes teve papel decisivo nessa história de sucesso.

Litto; Formiga et al. (2012, p. 3), afirmam também que se o Conselho de Ética e Constituição Brasileira; continuar a alterar artigos, parágrafos e/ou leis, desconhecendo a realidade da Coreia do Sul, o Brasil, continuará a margem do desenvolvimento educacional e consequentemente do seu desenvolvimento econômico.

O que levou o Brasil a oferecer cursos de capacitação através da EaD sem nenhuma portaria regulamentada em lei?

A resposta a essa pergunta é óbvia, o Brasil, viveu e ainda vive um preconceito cultural em relação a EaD. E segundo, Litto; Formiga et al. (2012, p. 3), boa parte dos recursos públicos da União é destinada as universidades presenciais, que consome um volume financeiro bem maior, são ineficientes e ainda, vivem em greves na maior parte do tempo acadêmico. Esses reflexos negativos só foram supridos, portanto com a promulgação da Lei Darcy Ribeiro, de 20 de dezembro do ano de 1996.

O Brasil, antes disso, já oferecia cursos de capacitação através da modalidade de EaD, não apresentando certificação, o que a rebaixava a condição de educação para as minorias, porquanto com a sanção em lei, Maia; Mattar (2007, p. 28); asseveram que:

$\checkmark$ A educação a distância surge oficialmente no Brasil pela Lei de Diretrizes e Bases da Educação Nacional (Lei n. 9.394, de 20 de dezembro de 1996), 
sendo normatizada pelo Decreto n. 2.494 (de 10 de fevereiro de 1998), pelo Decreto n. 2.561 (de 27 de abril de 1998) e pela Portaria Ministerial n. 301 (de 7 de abril de 1998).

$\checkmark$ A nova LDB reservou um artigo específico para o ensino e a educação a distância:

$\checkmark$ Art. 80. O Poder Público incentivará o desenvolvimento e a veiculação de programas de ensino a distância, em todos os níveis e modalidades de ensino, e de educação continuada.

$\checkmark \S 1^{\circ}$ A educação a distância, organizada com abertura e regime especiais, será oferecida por instituições especificamente credenciadas pela União.

$\checkmark \S 2^{\circ}$ A União regulamentará os requisitos para a realização de exames e registro de diploma relativos a cursos de educação a distância [sic].

$\checkmark \S 3^{\circ}$ As normas para produção, controle e avaliação de programas de educação a distância e a autorização para sua implementação caberão aos respectivos sistemas de ensino, podendo haver cooperação e integração entre os diferentes sistemas.

Com a criação de um artigo específico na $\mathrm{LDBEN}$, pode-se afirmar que a $\mathrm{EaD}$, passa do estagnado estágio de educação para as minorias, para uma modalidade de ensino regulamentada e que atualmente não perde para cursos da modalidade presencial, pois a EaD apresenta baixo custo, educação de ponta com professores doutores, mestres e especialistas; podendo expedir certificado e/ou diploma de mesmo valor se comparado aos de universidades presenciais.

O sucesso da EaD no Brasil, é tão grande após a sua inclusão na LDBEN, que o expresidente Lula - PT, sancionou uma resolução em 3 de abril de 2001, que segundo Maia; Mattar (2007, p. 31), a resolução de n. 1 dá autorização para o funcionamento de cursos de pós-graduação (lato-sensu) especialização e stricto-sensu (mestrado e doutorado).

A resolução diz também que os cursos de pós-graduação (lato-sensu), objeto de investigação desse estudo devem incluir necessariamente: provas presenciais e defesa presencial para os trabalhos de conclusão de curso.

\section{A FORMAÇÃO CONTINUADA DE PROFESSORES EM AMBIENTES DE APRENDIZAGEM VIRTUAL AVA}

Em tempos atuais é de extrema necessidade a formação continuada, não apenas de professores da educação básica, mas de todos os profissionais em geral. O processo de globalização, o avanço dos conhecimentos, das novas tecnologias da informação e da comunicação; obrigam os professores em especial a continuar se qualificando.

A formação inicial docente, hoje se torna obsoleta em pouco tempo; o que obriga esse professor da educação básica a investir na formação continuada, pois em virtude da ligeireza com que as informações chegam aos alunos e a sociedade civil em geral, os professores precisam: pesquisar, estudar e se qualificar cada vez mais para dar conta dessas novas 
informações, pois quem corre não são os professores em busca de novos conhecimentos, mas sim as informações pela forma como são postas em redes. E, neste sentido Castells (2006 apud ORTH et al, 2013, p. 44); “diria que se está vivendo em uma sociedade informacional, global e em redes".

A EaD, portanto é a única saída para o professor, pois em virtude dos baixos salários, da quantidade de horas-aulas dedicadas na escola e em casa, para o desenvolvimento de atividades pedagógicas e didáticas; o professor não tem tempo de investir em um curso presencial, pois nesta modalidade não existe a flexibilidade de horários, como existe na EaD.

Além disso, a EaD, também coloca este professor em sintonia com as novas informações e tecnologias educacionais, que na concepção de Orth et al. (2013, p. 44-5), ao mesmo tempo que a EaD, flexibiliza, ela também leva educação e, educação de qualidade, sendo uma nova forma de atualizar os profissionais docentes em suas respectivas áreas de formação a baixo custo e com qualidade comprovada por avaliações do MEC.

Litto; Formiga et al. (2012, p. 145), diz que em pleno século XXI, o professor ainda continua sendo o centro do processo ensino-aprendizagem, mas este mesmo professor, está longe da imagem do professor da época da invenção do quadro negro; continuar se qualificando é uma necessidade do professor deste novo século, e a EaD é o caminho; pois além da interação do professor com as novas tecnologias educacionais, ele também está se qualificando, uma premissa para quem deseja continuar em tempos modernos na sala de aula.

Quando o assunto é formação continuada, Romanowski (2007, p. 81); afirma que os propósitos de formação continuada para os professores brasileiros datam da década de 90, pois à atualização hoje dos conhecimentos; é uma necessidade, principalmente para aqueles que estão a professar sobre alguma coisa.

Alguns estudiosos, portanto depreciam à denominada expressão: "Formação Continuada de Professores", pois segundo a concepção destes, isso poderá denotar a falta de conhecimento para se está atuando na área da Educação. E neste sentido Gatti (2008 apud LOPES; FARIA, 2013, p. 89), apontam:

A formação continuada, como geralmente se apresenta, é uma prática que já traz em si uma contradição, pois ao se reafirmar constantemente sua necessidade, ao mesmo tempo está se afirmando que a formação inicial não foi satisfatória e que o professor não é capaz de se atualizar autonomamente.

Essa crítica é demasiadamente rústica. A formação continuada é condição sine qua non para que os professores acompanhem o ritmo de informações de que esta mesma sociedade do conhecimento impõem sobre os mesmos.

E, neste sentido Romanowski (2007, p. 6); afirma: 
A escola criada para possibilitar o acesso ao conhecimento, o 'ensinar tudo a todos', como definiu Comenius ${ }^{1}$, amplia seus propósitos para além de transmitir conhecimentos, de alfabetizar e diplomar, formar o cidadão culto, como nos séculos XVIII e XIX e assume, em tempos atuais, o preparar da mão-de-obra necessária ao desenvolvimento industrial e tecnológico.

A Educação a Distância surge como uma aliada para o processo de formação continuada, pois a sociedade atual têm enfrentado avanços no campo industrial e tecnológico; o que coloca a $\mathrm{EaD}$, como percursora. E para que esse professor atual acompanhe esse ritmo. É necessário que ele saiba usar as novas tecnologias da informação e da comunicação a seu favor; no planejar suas aulas, suas avaliações e outras atividades pedagógicas que necessitam de atualização constante. Uma vez que, a EaD aliada aos Ambientes de Aprendizagens Virtuais AVAs, possibilita a este professor que precisa de formação continuada e reciclagem o uso de tecnologias já mencionadas, para o aprender a aprender.

Com isso, Giolo (2008 apud ORTH et al. 2013, p. 47-8), diz que para se tornar um bom professor; o educador precisa mergulhar profundamente na vida cultural de seus alunos, e acrescenta que o aluno de hoje está cada vez mais conectado em redes, por isso, o professor além de uma boa formação, precisa dominar o uso das novas tecnologias educacionais. Portanto, a EaD, proporciona essa experiência, pois além da formação continuada; a EaD leva o professor a viver uma experiência em redes.

Sendo assim, os Ambientes de Aprendizagens Virtuais; tem contribuído decisivamente para esse tipo de conhecimento, pois neste novo processo de aprendizagem, o professor, aprende a percorrer por vários canais cibernéticos, e com isso, aprende a selecionar, compartilhar, direcionar e, além do mais, tudo isso tem refletido na sua prática pedagógica de sala de aula. E, como uma das propostas do MEC é levar formação inicial e continuada através destas plataformas de que dispõe o Ensino a Distância, já que a EaD leva conhecimento e aproxima esse mesmo professor da cultura que seus alunos vivenciam. Orth et al. (2013, p. 43), diz que as TIC, além de possibilitar a formação continuada de professores através de AVAs, também fornece uma experiência para a aplicabilidade dessas novas tecnologias educacionais na sala de aula.

Portanto, como definir AVAs? A esse respeito citaremos Faria; Lopes (2014, p. 49-50, grifos dos autores):

Os AVAs, LMSs, (learning management systems) ou sistema de gestão de aprendizagem SGA são softwares desenvolvidos sobre uma metodologia

\footnotetext{
${ }^{1}$ Reconhecido como um dos fundadores da pedagogia moderna, se dedicou a estudar a educação e propôs princípios para a educação que até hoje são levantados por estudiosos. Sua obra principal: A didática magna publicada em 1656. (MAZZOTTI, 1991).
} 
pedagógica para auxiliar a promoção de ensino e aprendizagem a distância ou semipresencial. Essas ferramentas, portanto, constituem plataformas educacionais que auxiliam no gerenciamento de aprendizagem.

Elas são as mais conhecidas e mais utilizadas ferramentas de comunicação de ensino e aprendizagem da $\mathrm{EaD}$. Um dos motivos é que, nessas plataformas, as quais, grosso modo, poderíamos chamar [sic] de salas online, o professor não só pode disponibilizar recursos utilizados como suporte para promover a aprendizagem e a produção do conhecimento, como vídeos, textos, materiais de apoio, atividades, mas também realizar fóruns, chats e outros. (FARIA; LOPES, 2014, p. 49-50, grifos dos autores).

Quando se fala de AVAs, é preciso deixar claro que essa metodologia de aprendizagem em $\mathrm{EaD}$, pode variar de órgão formador para órgão formador. A sigla nos remete a uma rota de aprendizagem, que pode e deve contemplar vídeos, chats, fóruns, textos, ou hyperibook apenas, pois quem vai determinar o que comtemplará esta rota de aprendizagem será a própria IES de ensino à distância ou semipresencial.

A expressão AVA, portanto, designa apenas uma rota de aprendizagem, ou melhor, é uma sala de aula. Uma sala de aula on-line, onde o estudante e o professor dispõe dos mais variados recursos metodológicos para o cumprimento do processo ensino-aprendizagem.

Portanto, Faria; Lopes (2014, p. 52), acrescentam ainda, que essas salas de aulas virtuais podem sofrer variações; a ideia central dessa metodologia em $\mathrm{EaD}$, é porquanto, o compartilhamento de links, materiais didáticos, e-books ${ }^{2}$ e, os recentes hiper-books ${ }^{3}$.

\subsection{A modalidade via E-learning o que é isso?}

A EaD, têm crescido bastante nos últimos tempos, especialmente no Brasil e especificamente no estado do Piauí. Entretanto, este crescimento se deve ao seu reconhecimento pela LDBEN.

Portanto, a EaD, além disso, oferece metodologias inovadoras para o processo ensinoaprendizagem; o E-learning, é apenas uma plataforma da EaD. Existem outras metodologias em EaD que facilitam a aprendizagem do estudante de EaD? Sim! Mas, aqui será mostrado a importância do E-learning, para o processo ensino-aprendizagem em EaD.

Tratar da EaD, é falar dos avanços em todos os setores da sociedade, do surgimento das novas tecnologias da informação e da comunicação TIC, pois a educação com o surgimento e avanço da internet tem usado as TIC, para atender as reais necessidades de aulas da educação a distância.

\footnotetext{
${ }^{2}$ São livros eletrônicos, em formato digital que podem ser lidos em computadores, PDA, leitor de livros digitais ou até mesmo celulares que tenham recurso para isso.

3 E uma espécie de livro digital, mas que conta com diversos recursos, como vídeos, músicas, textos, entre outros, com a finalidade de favorecer o processo de aprendizagem.
} 
E, a modalidade E-learning, tem sido a mais usada no campo da EaD; uma ferramenta que contribui para as relações síncronas e assíncronas entre alunos e professores dessa nova modalidade de ensino, pois com uso do computador, tablet, celular, subsidiado em rede, o Elearning, contribui para a execução de aulas por meio de vídeos, chats, videoaulas, fóruns, rádio web, etc. E, tudo isso, a um click de distância e durante as 24 horas do dia, quando e onde você quiser; e com a mesma qualidade dos cursos presenciais.

O E-learning, possibilita também ao aluno e professor; comunicação em tempo real conectado por uma rede de banda larga.

Sendo assim, Rosenberg (2002 apud BUTTIGNON; SILVA E GARCIA, 2002, p. 7); afirmam que o: "E-learning refere-se à utilização das tecnologias da Internet para fornecer um amplo conjunto de soluções que melhorem o conhecimento e o desempenho".

Ainda, segundo Buttignon, Silva e Garcia (2002, p. 8), o E-learning é um ensino eletrônico, que utiliza a internet para levar conhecimento aos lugares mais remotos deste país; utilizando essa modalidade de ensino o aluno estuda a qualquer hora e em qualquer lugar, sem necessidade de deslocamento para uma IES.

É preciso considerar, portanto que o tempo real em E-learning, corresponde exatamente ao número de acessos realizados a qualquer hora ao AVAs. Essa modalidade de ensino contempla também as relações assíncronas que são as relações que não se dão em tempo real, pois apenas um dos interessados obrigatoriamente deve estar online. Um exemplo desse tipo de relação é a participação do estudante nos fóruns, já que para este tipo de evento em E-learning, não há necessidade de todos os participantes estarem online ao mesmo tempo; existe para isso a possibilidade da troca de informações em momentos posteriores, pois quem controla esta participação, é o tutor através do ambiente AVA em EaD.

Buttignon, Silva e Garcia (2002, p. 8, grifos dos autores), acrescentam que:

O E-learning transpõe distâncias, mas a definição abrangente do aprendizado a distância também inclui cursos por correspondência, cursos unidirecionais pela televisão ou outras metodologias que não correspondem a nenhum dos critérios anteriores. [...] podemos dizer que o E-learning é uma forma de aprendizado a distância, mas o aprendizado a distância não é o E-learning.

Por fim, pode-se dizer que o E-learning, é apenas uma das várias metodologias presentes no ensino de EaD, sendo, portanto indispensável para a modalidade via E-learning o uso do computador, tablet, celular (android), etc, conectados a uma banda larga. 


\section{POR QUE A OPÇÃO PELA EDUCAÇÃO A DISTÂNCIA?}

Para que se alcançasse aos objetivos propostos para este estudo, foi realizada uma pesquisa bibliográfica e uma pesquisa de campo participante com 39 professores da educação básica do estado do Piauí, regularmente matriculados em um dos cursos de pós-graduação da área de educação do Centro Universitário Internacional UNINTER; polo presencial de PicosPI. Após o período da observação, foram realizadas entrevistas semiestruturadas com quatro perguntas acerca do tema abordado no trabalho.

As entrevistas foram realizadas pelo tutor que não acompanha o curso do entrevistado, para que o aluno entrevistado não se sentisse constrangido em expressar suas verdadeiras opiniões sobre as questões ali propostas.

De início, quis-se saber o porquê da escolha dessa modalidade de ensino e, como demonstrado na tabela, 56\% dos entrevistados responderam que o fator tempo foi o preponderante para a escolha, visto que, estes pós-graduandos, já possuem experiência profissional e de vida e que, em princípio o faz uma leitura equivocada do ensino a distância, até então, levando em consideração o que diz o Manual do Aluno do Centro Universitário Internacional UNINTER (2006 apud SILVA, 2011, p. 7):

$\checkmark$ São alunos adultos que dispõem de uma experiência de vida maior e, desse modo, encaram os estudos de uma forma diversa daqueles que estão iniciando a vida acadêmica.

$\checkmark$ São alunos que trazem para o ambiente de estudo suas experiências profissionais e estas influenciam no modo como irão estudar. Precisam desenvolver os estudos de forma paralela às suas atividades profissionais, uma vez que fatores diversos os impedem de frequentar os ambientes acadêmicos tradicionais.

$\checkmark$ Grande parcela dos alunos é formada por pessoas em ascensão e que necessitam completar seus estudos para elevar seu status social ou profissional.

$\checkmark$ São alunos potenciais do EaD as pessoas com idade mais avançada e que estão tendo a chance de completar sua formação.

Tabela 2 - Principal motivo da escolha da modalidade de Ensino a Distância

\begin{tabular}{l|c|c}
\hline \multicolumn{1}{c|}{ Principal Motivo } & Número de Pós-Graduandos & Percentual \\
\hline Tempo & 22 & $56 \%$ \\
\hline Facilidade da Modalidade & 14 & $36 \%$ \\
\hline Curso Desejado & 2 & $5 \%$ \\
\hline Localização da Instituição & 1 & $3 \%$ \\
\hline \multicolumn{2}{|c}{ Fonte: elaborada pelos autores. }
\end{tabular}

Por certo, 36\% responderam a essa questão dizendo que foi "a facilidade da modalidade e, principalmente, a facilidade de aprovação e a flexibilidade da frequência". Essa afirmação, portanto vai totalmente de desencontro a todos os procedimentos administrativos e acadêmicos do Polo de Apoio Presencial-PAP, pois, de maio/2010 a maio/2011, constatouse a desistência ou cancelamento do curso de 10,35\% dos alunos matriculados ou em processo de conclusão de curso, cujo principal motivo alegado foi há dificuldade e exigência encontrada 
nos cursos. Quanto às outras duas opções de respostas, 5\% dos entrevistados optou pela modalidade por oferecer o curso desejado e $3 \%$ disse que o principal motivo da escolha foi à oferta do curso dentro da macrorregião de seus domicílios.

Durante a entrevista também foram investigadas quais eram as principais expectativas desses pós-graduandos em relação à modalidade no tocante às exigências pedagógicas e acadêmicas da instituição, cujos resultados estão elencados na tabela 3.

\section{Tabela 3 - Principais expectativas em relação à modalidade de EaD}

\begin{tabular}{l|c|c}
\hline \multicolumn{1}{c|}{ Principal Expectativa } & Número de Alunos & Percentual \\
\hline Todas as Atividades Serão Via Internet & 5,6 & $14 \%$ \\
\hline Pouca Exigência e Compromisso & 23,2 & $60 \%$ \\
\hline O Sistema de Avaliação Será Facilitado & 10,2 & $26 \%$ \\
\hline A Frequência é Mais Flexível & 0,0 & $0 \%$ \\
\hline
\end{tabular}

Ao tutor e pesquisadores dos dados, a resposta com maior percentual a esta pergunta pareceu um pouco equivocada, visto que, desde o momento da matrícula, no treinamento introdutório que é ofertado aos alunos ingressantes e na aula inaugural ministrada pelos docentes da UNINTER e/ou pelo coordenador do curso escolhido, é enfatizado o tempo todo que o aluno irá desenvolver suas "atividades via internet". Portanto, a resposta para esse tipo de pergunta surpreendeu; por ter sido a menos indicada, das três apontadas em percentual a ser considerado para fins de resultados, o que surge como um equívoco, haja vista a modalidade de ensino que estes estejam matriculados; na modalidade via E-learning, não há aula, avaliação e/ou atividade presencial, pois até mesmo a defesa do TCC acontece online, porquanto no PAP, sob a inspeção do tutor e, via sistema AVA, conforme resolução contratual e resolução dada pelo o Ministério da Educação e Cultura.

Quanto à questão de "pouca exigência e compromisso" Schlünzen; Júnior (2011 apud SILVA, 2011, p. 9); classifica essa afirmação como mito:

[...] um curso de ensino a distância exige tanto - ou até mais - empenho do estudante quanto um presencial. Em vês de receber as informações mastigadas, do professor em sala de aula, o aluno de EAD precisa ter uma postura investigativa e pesquisar mais sobre os assuntos de seu interesse. Só assim, com independência temperada com responsabilidade, é possível avançar nos estudos.

Já, quanto às impressões dos pós-graduandos entrevistados a respeito do processo avaliativo, Romanowski (2007, p. 141); diz que: "as habilidades avaliativas direcionam a elaboração de julgamentos da importância dos resultados, como os obtidos pelos alunos nos testes escolares". 
Outro ponto relevante e, ao mesmo tempo contraditório também sobre este mesmo fator seria não encontrar nenhum pós-graduando, que viesse a indicar "o sistema de avaliação como facilitado", pois se trata primeiro de pessoas que conhecem bem a importância do ato de avaliar em qualquer nível de ensino.

O terceiro aspecto investigado nos pós-graduandos pesquisados; foi sobre os benefícios trazidos pela inserção na modalidade de educação à distância, conforme tabela 4 .

\section{Tabela 4 - Aspectos positivos trazidos pela EaD}

\begin{tabular}{l|c|c}
\hline \multicolumn{1}{c|}{ Principal Aspecto } & Número de Matriculados & Percentual \\
\hline Domínio das Tecnologias Informacionais & 19,5 & $50 \%$ \\
\hline Conhecimento de Novas Metodologias & 9,75 & $25 \%$ \\
\hline Tempo e Espaço do Curso (Aprendizagem) & 4,88 & $13 \%$ \\
\hline Canais de Comunicação Com os Docentes & 4,87 & $12 \%$ \\
\hline
\end{tabular}

Pelo percentual apresentado conclui-se que ao ingressar na modalidade EaD, grande parte dos pós-graduandos pesquisados nem sequer conhecem o significado da sigla AVA, mas ambos são verdadeiros quanto ao conhecimento e domínio das novas tecnologias da informação e comunicação aplicadas em sala de aula, o que tem contribuído para esse enquanto aluno de $\mathrm{EaD}$ e, professor do ensino básico do estado do PI.

Nesta era pós-industrial é necessário reconhecer o impacto das novas tecnologias da comunicação e da informação na sala de aula, pois estas terão um impacto cada vez maior na educação escolar seja ela a distância e/ou presencial, bem como, na vida cotidiana, pois segundo Libâneo (2002 apud SILVA, 2011, p. 10), é preciso que os professores modifiquem suas atitudes diante dos meios de comunicação, sob o risco de serem engolidos por eles. Assim, se exige do professor do século XXI, algumas competências como:

a) capacitação constante;

b) capacidade de aprender e aprender;

c) domínio da linguagem informacional;

d) saber usar meios de comunicação e articular as aulas com as mídias e multimídias.

E, quanto à escola, é preciso formar o novo professor, modificando a forma que ele tem de pensar e utilizar a tecnologia, pois só assim estará preparado para trabalhar corretamente com ela.

A última pergunta feita aos pós-graduandos poderia ter sido a primeira a ser feita, porém, para que se evitasse "maquiagens" nas respostas às perguntas anteriores e se ter 100\% de sinceridade nesta última, por ter se debatido sobre os outros temas, esta foi reservada, estrategicamente, para o final, ver tabela 5. 
Tabela 5 - Por que da procura por um curso de pós-graduação

\begin{tabular}{l|c|c}
\hline \multicolumn{1}{c|}{ Principal Motivo } & Número de Pós-Graduandos & Percentual \\
\hline Progressão Salarial & 30 & $77 \%$ \\
\hline Qualificação Profissional & 6 & $15 \%$ \\
\hline Exigência do Mercado & 2 & $5 \%$ \\
\hline Cobrança da Família/Amigos & 1 & $3 \%$ \\
\hline
\end{tabular}

Como já mencionado no início deste estudo, todos os pós-graduandos entrevistados possuem a ação docente como profissão na rede pública, limitando-se ao estado do Piauí, na esfera federal, estadual e/ou municipal. Com isso, entende-se porque a progressão salarial é o principal motivo da procura por um curso de pós-graduação, visto que, nas três esferas, existem planos de cargos e salários específicos para professores que têm seus soldos embasados na sua formação e pós-formação. Contudo, sobre qualificação profissional (formação continuada) Romanowski (2007, p. 131-2); diz:

[...] os programas de formação, ao possibilitarem conhecimentos sobre a escola e o sistema educativo e ao explicitarem a complexidade das situações de ensino e as possíveis alternativas de solução, a partir da prática, favorecem uma ação docente mais crítica e consciente.

$\cdots$

O professor iniciante, além da limitação de conhecimentos da prática e da experiência, necessita aprofundar seus conhecimentos teóricos para ser capaz de explicitar situações de impasse. São necessários serviços de apoio a esse professor, para ajuda-lo a aplicar os conhecimentos que já possui e melhorar os processos de investigação para obter conhecimentos por si próprio.

Com isso fica claro que não basta fazer um curso de pós-graduação meramente para obtenção do título. É necessário que este curso seja vivenciado, aproveitado, que o professor invista com fervor em sua pós-formação, até porque muitos não o são DE (dedicação exclusiva) e também trabalham na rede particular de ensino. Isso implica dizer que suas práticas docentes e habilidades podem estar sendo observadas de forma mais crítica e pessoal, ou seja, em uma escola particular ele não é só mais um número de matrícula na folha de pagamento, ele é um professor que deverá mostrar na prática aptidões e qualificação do título imposto por sua especialização.

\section{CONSIDERAÇÕES FINAIS}

Conclui-se que a maioria dos professores do estado do Piauí, que procura a educação à distância como opção para cursos de pós-graduação, inicialmente, tem uma visão equivocada da modalidade de ensino, pois buscam facilidades acadêmicas e pedagógicas que não teriam no ensino regular presencial. Por outro lado, foi bem animador constatar, que quem

Revista RENOVE, versão On-line, Camaçari, v.1, n.1, 2020. 
resiste ao impacto de tantas novidades e avanços tecnológicos no processo ensinoaprendizagem, é realmente conquistado pelo sistema e permanece estudando no polo pesquisado; passam a fazer uma leitura diferente da $\mathrm{EaD}$, mediante a intervenção dos professores e tutores nas práticas não compatíveis com ensino de qualidade, seriedade e compromisso com a educação.

Face ao preconceito ainda tão arraigado com a modalidade, o calouro do ensino a distância é um sujeito altamente desconfiado da idoneidade do sistema e, mais uma vez, cabe aos profissionais docentes do UNINTER, assegurar que a qualidade da aprendizagem e o bom andamento dos processos concernentes à estrutura acadêmica e pedagógica da educação à distância, superem as expectativas desses alunos.

Também é de fundamental importância que seja investido esforços, no sentido de adaptar a escola e capacitar os profissionais da educação em tecnologias da comunicação e da informação, exigências do século XXI. É necessário que pesquisas sobre estas tecnologias sejam realizadas, para que se possa acompanhar a sua evolução e utilizá-las em benefício da escola e dos docentes.

Assim, as novas tecnologias podem reforçar a contribuição dos trabalhos pedagógicos e didáticos contemporâneos, pois permitem que sejam criadas situações de aprendizagem ricas, complexas, diversificadas, por meio de uma divisão de trabalho interativo entre o professor e os produtores dos instrumentos informacionais. Isso minimizará sensivelmente o impacto sofrido por esse professor no momento que necessitar se inserir em qualquer curso na modalidade a distância.

Quanto a diferença entre EaD e, ensino presencial, pode-se dizer que essa diferença esteja na estrutura, pois a $\mathrm{EaD}$, tem oferecido cursos de qualidade a baixo custo, portanto sua estrutura é inovadora; possibilita o docente matriculado em um de seus cursos, a levar para a prática novas metodologias para o processo ensino-aprendizagem.

Ainda há muito a se discutir sobre o tema, por isso, esse artigo não deve e nem será encerrado aqui, pois o processo, embora não pareça, é bastante complexo e ainda há muitos tabus a serem quebrados, porém com determinação e profissionalismo de todos que compõem a educação a distância a jornada ainda é lenta, mas consistente. Os resultados obtidos com esta investigação poderão auxiliar não só a professores conteudistas, professores-tutores e demais docentes do PAP em questão e da Instituição UNINTER, mas também a qualquer profissional e estudioso do assunto, no sentido de subsidiar as futuras pesquisas e planejamento realizados para melhorias e consolidação da EaD no Brasil e no mundo. 


\section{REFERÊNCIAS}

ALMEIDA, Maria Elizabeth Bianconcini de. Educação a distância na internet: abordagens e contribuições dos ambientes digitais de aprendizagem. Educação e Pesquisa, São Paulo, v. 29, n. 2, p. 327-340, jul./dez. 2003. Disponível em: < http://www.scielo.br/pdf/ep/v29n2/a10v29n2.pdf>. Acesso em: 20 out. 2014.

BELLONI, Maria Luiza. Educação a distância. 6. ed. Campinas, SP: Autores Associados, 2012. (Coleção Educação Contemporânea).

BUTTIGNON, Karina; SILVA, Marcelo Heleodoro da; GARCIA, Rosilene Pereira César. Uma Reflexão Sobre o Ensino a Distância, via Internet, no Brasil. 2002. 63 f. Trabalho de Conclusão de Curso (Monografia) - Especialização em Informática Empresarial. Universidade Estadual Paulista, Faculdade de Engenharia de Guaratinguetá, São Paulo, 2002. Disponível em: http://www.conhecer.org.br/download/cp/NOVAS\%20TECNOLOGIAS/M3/leitura\%20ane xa\%203.pdf >. Acesso em: 20 out. 2014.

FARIA, Adriano Antônio; LOPES, Luís Fernando. Práticas pedagógicas em EaD. 1ª ed. Curitiba: Intersaberes, 2014. (Série Tecnologias Educacionais).

FARIA, Raquel Caixeta. EaD - Democratizando a Educação Através da Modalidade a Distância. 2011. 23 f. Trabalho de Conclusão de Curso (Graduação) - Licenciatura em Ciências Biológicas. Universidade de Brasília, DF, 2011. Disponível em: $<$ http://www.fe.unb.br/catedraunescoead/areas/menu/publicacoes/monografias-sobre-ticsna-educacao/ead-democratizando-a-educacao-atraves-da-modalidade-a-distancia>. Acesso em: 20 out. 2014.

LITTO, Michael Fredric; FORMIGA, Marcos. (Org.). Educação a distância: o estado da arte. 2. ed. São Paulo: Pearson Education do Brasil, 2012. v. 2.

LOPES, Luís Fernando; FARIA, Adriano Antônio. O que e o quem da EaD: história e fundamentos. 1. ed. Curitiba: Intersaberes, 2013. (Série Fundamentos da Educação).

MAIA, Carmem; MATTAR, João. ABC da EaD. 1. ed. São Paulo: Pearson Prentice Hall, 2007. $8^{\text {a }}$. reimpressão.

MORAES, Reginaldo C. Educação a distância e ensino superior: introdução didática a um tema polêmico. 1. ed. São Paulo: Senac, 2010. (1. Educação a Distância. 2. Ensino Superior. 3. Ensino Universitário).

ORTH, Miguel Alfredo et al. Ambientes virtuais de aprendizagem e formação continuada de professores na modalidade a distância. Conjectura, Caxias do Sul, v. 18, n. 1, p. 42-58, jan./abr. 2013. Disponível em: < http://www.ucs.br/etc/revistas/index.php/conjectura/article/viewFile/2037/1200 >. Acesso em: 04 jan. 2015.

ROMANOWSKI, Joana Paulin. Formação e profissionalização docente. 3. ed. Curitiba: Ibpex, 2007. 4a . reimpressão. (1. Professores - Formação. 2. Prática de Ensino).

SILVA, Ana Paula de Oliveira Souza e. Profissionais de Educação Como Alunos da Educação a Distância (EaD): dificuldades, resistências e avanços. Facinter, [Curitiba], p. 01-14, mai. 2011. 
SOUZA, Anderson Gomes de (org.). O impacto da educação a distância no ensino superior: Uma análise na perspectiva dos alunos e docentes da Universidade Federal de Pernambuco. Revista Ibero-americana de Educação, Centro de Estudos em Hospitalidade. CHT/UFP, n. 58/1, p. 01-10, jan. 2012. Disponível em: http://www.rieoei.org/deloslectores/4403Gomes.pdf>. Acesso em: 20 out. 2014. 